\title{
IDUA Gene Variants and Response to Zoledronic Acid Treatment in Chinese Women with Postmenopausal Osteoporosis
}

\author{
Haiqing Lin ${ }^{\prime}$ \\ Jin $\mathrm{Li}^{1}$ \\ Zhonghua $\mathrm{Xu}^{2}$ \\ Ting $\mathrm{Liu}^{3}$ \\ Xindie Zhou (iD ${ }^{3}$ \\ 'Department of Orthopedic Surgery, the \\ Second Affiliated Hospital of Jiaxing \\ University, Jiaxing, 3 I 4000, People's \\ Republic of China; ${ }^{2}$ Department of \\ Orthopedics, Jintan Hospital Affiliated to \\ Jiangsu University, Changzhou, 213200, \\ People's Republic of China; ${ }^{3}$ Department \\ of Orthopedics, The Affiliated \\ Changzhou No.2 People's Hospital of \\ Nanjing Medical University, Changzhou, \\ 213003, People's Republic of China
}

Correspondence: Ting Liu; Xindie Zhou Department of Orthopedics, The Affiliated Changzhou No.2 People's Hospital of Nanjing Medical University, Changzhou, 213003, People's Republic of China Email 1418583360@qq.com;

zhouxindie@njmu.edu.cn
Purpose: Alpha-L-iduronidase (IDUA) rs3755955 and rs6831280 polymorphisms have been demonstrated to be associated with bone mineral density (BMD). However, no study has investigated the association of these two polymorphisms with osteoporosis (OP) susceptibility in Chinese postmenopausal women.

Patients and Methods: IDUA gene polymorphisms were genotyped in 278 women with OP and 303 healthy controls via polymerase chain reaction and Sanger sequencing.

Results: Our data indicated that IDUA rs3755955 and rs6831280 polymorphisms increased the risk of OP in homozygous, dominant, and allelic models. We observed lower lumbar spine BMD in younger women with the AA genotype of rs 3755955 polymorphism. Finally, mutant genotypes with rs6831280 polymorphism were more sensitive to zoledronic acid treatment, and the treatment effect was significant in terms of BMD levels.

Conclusion: In conclusion, IDUA rs3755955 and rs6831280 polymorphisms demonstrated susceptibility to OP in Chinese postmenopausal women. IDUA rs6831280 polymorphism caused differences in response to zoledronic acid treatment.

Keywords: IDUA, polymorphism, zoledronic acid, postmenopausal osteoporosis

\section{Introduction}

Osteoporosis (OP) is a metabolic bone disorder characterized by low bone mass and micro-architectural deterioration of the bone tissue. ${ }^{1}$ OP increases the risk of bone fractures, which are associated with increased mortality and low quality of life. ${ }^{2}$ Postmenopausal OP and osteoporotic fractures are common, particularly among older women. ${ }^{3}$ As there are no signs or symptoms of OP other than bone fractures, risk assessment for OP is necessary to identify individuals at higher risks of future clinical events. ${ }^{4} \mathrm{~A}$ diagnosis of OP can be made based on low bone mineral density (BMD) measured by dual-energy X-ray absorptiometry. ${ }^{5}$ In a meta-analysis of genome-wide association studies, different BMD phenotypes were found to be associated with alpha-L-iduronidase (IDUA) gene polymorphisms. ${ }^{6}$

IDUA regulation has been demonstrated to affect bone formation. For instance, IDUA-deficient mice progressively developed a high bone mass phenotype with pathological lysosomal storage in cells of osteoblast lineage. ${ }^{7}$ Histomorphometric quantification further helped identify shortening of bone-forming units in these mice and a reduced quantity of osteoclasts per bone surface. ${ }^{7}$ In addition, an upregulation of IDUA was observed in osteoporotic patients compared with healthy 
older adults. ${ }^{8}$ Within the IDUA protein, it is hypothesized that the phosphorylation site T366 is indirectly affected by IDUA rs6831280 (A361T) and phosphorylation sites T98 and S102 are affected by IDUA rs3755955 (R105Q). ${ }^{6}$ To this end, Wang et al recruited 328 OP patients, with or without osteoporotic fractures, to evaluate the association of IDUA gene polymorphisms with BMD and fractures in Chinese elderly patients with OP. ${ }^{9}$ They found that IDUA rs6831280 polymorphism was associated with BMDs at L2-L4 and total hip BMD. ${ }^{9}$ In this study, we aim to validate this finding in Chinese women with postmenopausal OP.

Optimal protein and calcium intake, vitamin D supply, and inhibition of smoking and drinking, together with regular weight-bearing physical exercise, are the corner stones for OP and/or osteoporotic fracture prevention. ${ }^{2}$ Several drugs are licensed to reduce fracture risk by slowing down bone resorption (eg, bisphosphonates and denosumab) or by stimulating bone formation (eg, teriparatide). ${ }^{1}$ Zoledronic acid (ZA) is an intravenous, highly potent aminobisphosphonate used in patients with primary or secondary OP or low bone mass. ${ }^{10}$ Its high affinity and long half-life in bones and long duration of action allow for a once-yearly administration. ${ }^{10}$ Therefore, we intended to explore the role of these two polymorphisms of IDUA gene in OP susceptibility and the therapeutic effect of intravenous ZA administration in Chinese postmenopausal women.

\section{Patients and Methods Subjects}

From April 2014 to August 2017, three hospitals (Jintan Hospital Affiliated to Jiangsu University, the Affiliated Changzhou No. 2 People's Hospital of Nanjing Medical University, and the Second Affiliated Hospital of Jiaxing University) continuously recruited 660 Chinese postmenopausal women ( $>1$ year since menopause), including 357 OP patients and 303 healthy controls. BMD was measured by trained technicians at the lumbar spine (L2-L4) and femoral neck via dual-energy X-ray absorptiometry (Lunar Radiation Corp., Madison, WI, USA). The daily inter-rater variation coefficient was within normal operational standards and in vivo variation coefficient was lower than $1.5 \%$. Based on the definition by the World Health Organization (WHO), the presence of OP was characterized by a BMD T-score of less than -2.5 either at the femoral neck or lumbar spine. Those who had undergone oophorectomy or those who exhibited premature ovarian failure, thyroid disease, rheumatoid arthritis, hypercortisolism, calcium intake disorders, gastrointestinal, and/or renal diseases; those under the age of 40 years; and those who had a history of abnormal bone metabolism or use of medication interfering with bone metabolism were excluded from the investigation.

The annual treatment cost for ZA is equivalent to other oral anti-OP drugs; furthermore, it is easy to use and has good compliance and high bioavailability. Therefore, the OP patients were recommended to use ZA after a kidney function test (creatinine clearance rate $\geq 35 \mathrm{~mL} / \mathrm{min}$ ). Each enrolled OP patient received intravenous ZA once a year for 3 years. Intravenous ZA was administered at a dose of $5 \mathrm{mg}$ per $100 \mathrm{~mL}$ of $0.9 \%$ saline solution with a standardized duration of 30 to $40 \mathrm{~min}$. Patients received $500 \mathrm{~mL}$ of intravenous saline before/after ZA infusion. Daily supplementation with calcium $(500 \mathrm{mg})$ and vitamin D (400 IU) was strongly recommended. However, 9 OP patients with severe cognitive impairment, bisphosphonate-related osteonecrosis of the jaw, allergy, and previous ZA contraindications were excluded during treatment. In all, 70 OP patients did not complete the entire treatment process. We finally performed data analysis on 278 OP patients and 303 healthy controls. The response to ZA treatment was evaluated based on the trend of BMD in the lumbar spine. An increase in lumbar spine BMD exceeding $0.05 \mathrm{~g} / \mathrm{cm}^{2}$ was indicative of effective treatment, and any results otherwise were suggestive of ineffective treatment. Accordingly, the OP patients were divided into responders and non-responder groups with respect to ZA treatment. Individuals in the control group did not have a previous history of OP and/or fractures and were age matched to the participants with OP. All participants were of Chinese Han ethnicity and were genetically unrelated. Daily physical activity, menstrual history, and family history concerning the incidence of fractures were obtained from all participants. Data regarding calcium and vitamin D intake were also collected through a structured questionnaire. Body mass index (BMI) was calculated as weight in kilograms divided by the square of the height in meters. Written informed consent was obtained from all participants in the study before enrollment. Confidentiality of personal and medical data was conducted in accordance with the Helsinki declaration. The Clinical Ethics Committee of the aforementioned three hospitals [Jintan Hospital Affiliated to Jiangsu University (ID: KY-2014010), the Affiliated Changzhou No. 2 People's Hospital of 
Table I Patient Demographics and Risk Factors in Osteoporosis

\begin{tabular}{|l|c|c|c|}
\hline Characteristics & Case (N=278) & Control (N=303) & $P$ \\
\hline Age, years & $62.78 \pm 8.40$ & $62.74 \pm 8.30$ & 0.968 \\
\hline BMI, kg/m & $24.39 \pm 1.44$ & $24.23 \pm 1.54$ & 0.232 \\
\hline Vitamin D intake, IU/day & $205.62 \pm 79.11$ & $146.17 \pm 65.29$ & $<0.001$ \\
\hline Calcium intake, mg/day & $849.21 \pm 120.17$ & $705.49 \pm 117.58$ & $<0.001$ \\
\hline $\begin{array}{l}\text { Diabetes } \\
\text { Yes }\end{array}$ & $97(34.9 \%)$ & $78(25.7 \%)$ & 0.016 \\
\hline No & $181(65.1 \%)$ & $225(93.1 \%)$ & $<1.01 \pm 0.06$ \\
\hline Lumbar spine BMD, g/cm & $0.73 \pm 0.07$ & $0.95 \pm 0.07$ & $<0.001$ \\
\hline Femoral neck BMD, g/cm & $0.66 \pm 0.06$ & & $<0.001$ \\
\hline
\end{tabular}

Abbreviations: BMI, body mass index; BMD, bone mineral density.

Nanjing Medical University (ID: [2017] KY008-01), and the Second Affiliated Hospital of Jiaxing University (ID: JXEY-2015SW68)] approved this investigation.

\section{Blood Sampling and Genotyping}

Blood samples collected from each participant were used to genotype polymorphisms. Genomic DNA was isolated from peripheral leukocytes using the TIANamp Blood DNA kit (Qiagen, Hilden, Germany). We selected single nucleotide polymorphisms (SNPs) in the IDUA gene according to the following criteria: minor allele frequency $>5 \%$ and significant association with BMD or BMDrelated risk factors reported in previous studies.

IDUA gene polymorphisms were genotyped via polymerase chain reaction (PCR) and Sanger sequencing (Genesky Biotechnologies Inc., Shanghai, China). The primers used in this study were as follows: rs3755955: 5'-CGCAGC ATCAGAACCTGCTACT-3' (forward); 5'-CGGGTGTT GTTGACCTGGAAG-3' (Reverse); rs6831280: 5'TCTGAAACTGTCCTGTTGACTCAG-3' (forward); 5'ATCAATGTTGAGCAATTGTCAG-3' (Reverse).

Five percent of the samples were repeatedly genotyped to ensure the validity of the genotyping methods.

\section{Statistical Analysis}

A chi-square test was used to evaluate the differences in categorical variables and percentages were used between two groups. The mean and SD of continuous variables were calculated and tested using Student's $t$-test or an analysis of variance. Deviation from Hardy-Weinberg equilibrium (HWE) for IDUA gene polymorphisms was assessed among the control individuals using chi-square test. Logistic regression analysis was applied to calculate the odds ratios (ORs) and 95\% confidence intervals (95\% CI) for evaluating the association between IDUA gene polymorphisms and the risk of OP. A value of $P<0.05$ was considered statistically significant. All data were analyzed using SPSS 22.0 software (SPSS Inc., Chicago, USA).

\section{Results}

\section{Characteristics of the Study Population}

Baseline participant characteristics are shown in Table 1. The case group comprised 278 postmenopausal women with a mean age of $62.78 \pm 8.40$ years and BMI of $24.39 \mathrm{~kg} / \mathrm{m}^{2}$. Among all participants, most women (65.1\%) did not have diabetes; however, the number of women with diabetes differed significantly between groups $(P=0.016)$. There was a significant difference between vitamin $\mathrm{D}$ and calcium intake and lumbar spine/femoral neck BMD between participants with OP and healthy controls $(P<0.001)$.

\section{IDUA Gene Variant Analysis}

The genotype distribution information of the two SNPs in IDUA is provided in Table 2. The A allele frequencies of IDUA rs3755955 and rs6831280 polymorphisms were $19.4 \%$ and $27.2 \%$ among participants, with OP and $13.5 \%$ and $21.3 \%$ among healthy controls, respectively. The genotype distribution of these two polymorphisms was in agreement with HWE in the healthy control group.

Our study demonstrated that the AA genotype or A allele of IDUA rs3755955 polymorphism was associated with an increased risk of OP (AA vs GG: OR, 
Table 2 Genotype Frequencies of IDUA Gene Polymorphisms in Cases and Controls

\begin{tabular}{|c|c|c|c|c|c|c|c|}
\hline Models & Genotype & Case, n (\%) & Control, n (\%) & OR (95\% Cl) & $P$-value & $*$ OR $(95 \% \mathrm{Cl})$ & $* P$-value \\
\hline \multicolumn{8}{|l|}{ Rs3755955 } \\
\hline Wild & GG & $184(66.2)$ & 227 (74.9) & 1.00 (reference) & - & 1.00 (reference) & - \\
\hline Heterozygote & GA & $80(28.8)$ & $70(23.1)$ & $I .4 \mathrm{I}(0.97,2.05)$ & 0.073 & $1.40(0.96,2.04)$ & 0.081 \\
\hline Homozygote & $\mathrm{AA}$ & $14(5.0)$ & $6(2.0)$ & $2.88(1.08,7.64)$ & 0.034 & $2.85(1.06,7.61)$ & 0.037 \\
\hline Dominant & $\begin{array}{l}\text { GG } \\
G A+A A\end{array}$ & $\begin{array}{l}184(66.2) \\
94(33.8)\end{array}$ & $\begin{array}{l}227(74.9) \\
76(25.1)\end{array}$ & $\begin{array}{l}1.00 \text { (reference) } \\
1.53(1.07,2.19)\end{array}$ & $\begin{array}{l}- \\
0.021\end{array}$ & $\begin{array}{l}1.00 \text { (reference) } \\
1.5 \mathrm{I}(\mathbf{1 . 0 5 , 2 . 1 7 )}\end{array}$ & $\begin{array}{l}- \\
0.025\end{array}$ \\
\hline Recessive & $\begin{array}{l}\text { GG+GA } \\
A A\end{array}$ & $\begin{array}{l}264(95.0) \\
14(5.0)\end{array}$ & $\begin{array}{l}297(98.0) \\
6(2.0)\end{array}$ & $\begin{array}{l}1.00 \text { (reference) } \\
2.62(0.99,6.93)\end{array}$ & $\begin{array}{l}- \\
0.051\end{array}$ & $\begin{array}{l}1.00 \text { (reference) } \\
2.60(0.98,6.92)\end{array}$ & $\begin{array}{l}- \\
0.056\end{array}$ \\
\hline Allele & $\begin{array}{l}\mathrm{G} \\
\mathrm{A}\end{array}$ & $\begin{array}{l}448(80.6) \\
108(19.4)\end{array}$ & $\begin{array}{l}524(86.5) \\
82(13.5)\end{array}$ & $\begin{array}{l}1.00(\text { reference) } \\
1.54(1.13,2.11)\end{array}$ & $\begin{array}{l}- \\
0.007\end{array}$ & & \\
\hline Rs683। 280 & & & & & & & \\
\hline Wild & GG & $148(53.2)$ & $186(6 \mid .4)$ & 1.00 (reference) & - & 1.00 (reference) & - \\
\hline Heterozygote & GA & $109(39.2)$ & $105(34.7)$ & I. $31(0.93, I .84)$ & 0.130 & $1.35(0.95,1.91)$ & 0.091 \\
\hline Homozygote & AA & $21(7.6)$ & $12(4.0)$ & $2.20(1.05,4.62)$ & 0.037 & $2.42(1.14,5.1 I)$ & 0.021 \\
\hline Dominant & $\begin{array}{l}\mathrm{GG} \\
\mathrm{GA}+\mathrm{AA}\end{array}$ & $\begin{array}{l}\text { I } 48(53.2) \\
\text { I } 30(46.8)\end{array}$ & $\begin{array}{l}186(61.4) \\
117(38.6)\end{array}$ & $\begin{array}{l}1.00 \text { (reference) } \\
1.40(1.00,1.94)\end{array}$ & $\begin{array}{l}- \\
0.047\end{array}$ & $\begin{array}{l}\text { I.00(reference) } \\
1.45(1.04,2.03)\end{array}$ & $\begin{array}{l}- \\
0.028\end{array}$ \\
\hline Recessive & $\begin{array}{l}\mathrm{GG}+\mathrm{GA} \\
\mathrm{AA}\end{array}$ & $\begin{array}{l}257(92.4) \\
21(7.6)\end{array}$ & $\begin{array}{l}291(96.0) \\
12(4.0)\end{array}$ & $\begin{array}{l}\mathrm{I} .00 \text { (reference) } \\
\mathrm{I.98}(0.96,4.1 \mathrm{I})\end{array}$ & $\begin{array}{l}- \\
0.066\end{array}$ & $\begin{array}{l}\text { I.00(reference) } \\
2.14(1.03,4.46)\end{array}$ & $\begin{array}{l}- \\
0.042\end{array}$ \\
\hline Allele & $\begin{array}{l}G \\
A\end{array}$ & $\begin{array}{l}405(92.8) \\
15 \mid(27.2)\end{array}$ & $\begin{array}{l}477(78.7) \\
129(21.3)\end{array}$ & $\begin{array}{l}\text { I.00(reference) } \\
\text { I.38(I.05,I.8I) }\end{array}$ & $\begin{array}{l}- \\
0.020\end{array}$ & - & - \\
\hline
\end{tabular}

Notes: Bold values are statistically significant $(P<0.05)$. *Adjust for age, body mass index and diabetes mellitus.

2.88; 95\% CI, 1.08-7.64; P = 0.034; A vs G: OR, 1.54; 95\% CI, $1.13-2.11 ; \mathrm{P}=0.007)$. Similarly, GA+AA genotype had a 1.53 -fold higher risk of OP than the GG genotype. Furthermore, IDUA rs6831280 polymorphism conferred susceptibility to OP under the homozygous, dominant, and allelic models. These associations remained significant after adjusting for age, BMI, and diabetes mellitus. Additionally, IDUA rs6831280 polymorphism increased the risk of OP in the recessive model.

We further investigated the association of IDUA gene polymorphisms with the demographic (ie, age and BMI) and clinical data (ie, diabetes and lumbar spine/femoral neck BMD) (Table 3). For rs3755955, the age of the AA genotype carrier was found to be significantly younger than that of the GA/GG genotype carriers. In addition, IDUA rs3755955 polymorphism was significantly associated with lumbar spine BMD, with the AA genotype having the lowest BMD. Furthermore, the femoral neck BMD of the AA genotype carrier in rs3755955 polymorphism was significantly lower than that of $\mathrm{GA} / \mathrm{GG}$ genotype carriers. However, no significant association with clinical parameters was found for rs6831280 polymorphism.

\section{IDUA Gene Polymorphisms and ZA}

\section{Treatment}

We recorded baseline characteristics of responders $(61.5 \%$ of participants) and non-responders to ZA treatment (Table 4). The mean age and BMI of responders and nonresponders were not significantly different (all $P>0.05$ ). Similarly, among responders, there was no significant difference between participants with OP and healthy controls with regard to vitamin $\mathrm{D}$ and calcium intake, diabetes status, and lumbar spine/femoral neck BMD.

Furthermore, this study investigated the effect of these two polymorphisms on the therapeutic effect of intravenous ZA (Table 5). There was no significant difference in the genotypic distribution of rs3755955 polymorphism between responders and non-responders to ZA treatment. 


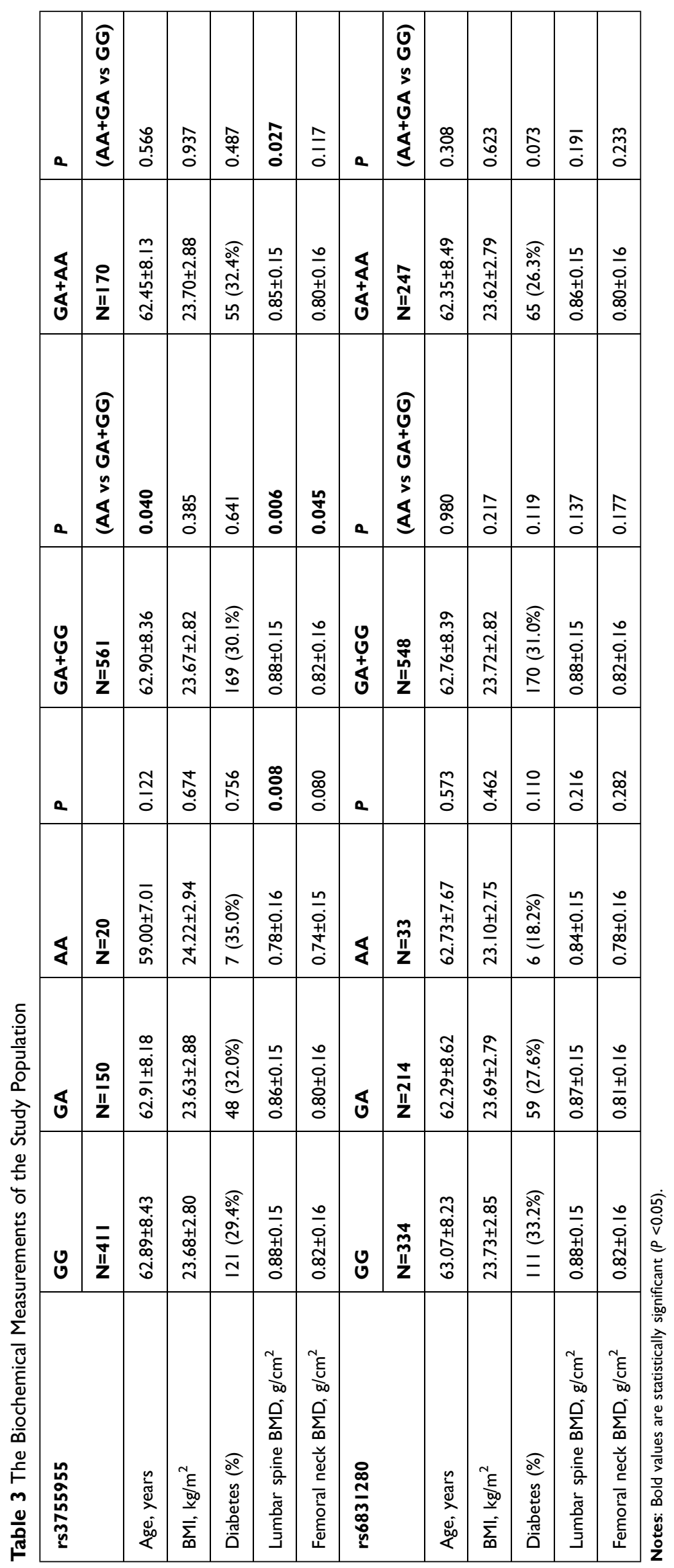


Table 4 Clinical Characteristics of Patients Treated with Aclasta

\begin{tabular}{|l|c|c|c|}
\hline Characteristics & Non-Responders & Responders & $\boldsymbol{P}$ \\
\hline Number (\%) & $107(38.5)$ & $171(61.5)$ & 0.716 \\
\hline Age, years & $63.01 \pm 7.83$ & $62.63 \pm 8.77$ & 0.020 \\
\hline BMl, kg/m ${ }^{2}$ & $24.23 \pm 2.78$ & $23.42 \pm 2.85$ & 0.916 \\
\hline Vitamin D intake, IU/day & $206.25 \pm 80.75$ & $205.22 \pm 78.31$ & 0.770 \\
\hline Calcium intake, mg/day & $846.53 \pm 123.01$ & $850.88 \pm 118.70$ & 0.269 \\
\hline $\begin{array}{l}\text { Diabetes } \\
\text { Yes }\end{array}$ & $65(60.7 \%)$ & $115(67.3 \%)$ & $56(32.7 \%)$ \\
\hline No & $42(39.3 \%)$ & $0.73 \pm 0.07$ & 0.252 \\
\hline Lumbar spine BMD, g/cm & $0.72 \pm 0.06$ & $0.67 \pm 0.06$ & 0.511 \\
\hline Femoral neck BMD, g/cm & $0.66 \pm 0.06$ & & \\
\hline
\end{tabular}

Abbreviations: BMI, body mass index; BMD, bone mineral density.

Table 5 The Distribution of Genotype Frequencies of IDUA Gene Polymorphisms in Responders and Non-Responders

\begin{tabular}{|c|c|c|c|c|c|c|c|}
\hline Models & Genotype & Non-Responders, n (\%) & Responders, n (\%) & OR (95\% CI) & $P$-value & *OR (95\% Cl) & *P-value \\
\hline \multicolumn{8}{|l|}{ Rs3755955 } \\
\hline Wild & GG & $75(70.1)$ & $109(63.7)$ & 1.00 (reference) & - & 1.00 (reference) & - \\
\hline Heterozygote & GA & $24(22.4)$ & $56(32.7)$ & $0.62(0.36,1.09)$ & 0.098 & $0.64(0.36, I .13)$ & 0.122 \\
\hline Homozygote & AA & $8(7.5)$ & $6(3.5)$ & $1.94(0.65,5.81)$ & 0.238 & $2.00(0.65,6.14)$ & 0.226 \\
\hline Dominant & $\begin{array}{l}G G \\
G A+A A\end{array}$ & $\begin{array}{l}75(70.1) \\
32(29.9)\end{array}$ & $\begin{array}{l}109(63.7) \\
62(36.3)\end{array}$ & $\begin{array}{l}\text { I.00(reference) } \\
0.75(0.45,1.26)\end{array}$ & $\overline{-}$ & $\begin{array}{l}1.00 \text { (reference) } \\
0.77(0.45,1.30)\end{array}$ & $\overline{-}$ \\
\hline Recessive & $\begin{array}{l}\text { GG+GA } \\
A A\end{array}$ & $\begin{array}{l}99(92.5) \\
8(7.5)\end{array}$ & $\begin{array}{l}165(96.5) \\
6(3.5)\end{array}$ & $\begin{array}{l}\text { I.00(reference) } \\
2.22(0.75,6.59)\end{array}$ & - & $\begin{array}{l}\text { I.00(reference) } \\
2.29(0.75,6.93)\end{array}$ & $\begin{array}{l}- \\
0.144\end{array}$ \\
\hline Allele & $\begin{array}{l}\mathrm{G} \\
\mathrm{A}\end{array}$ & $\begin{array}{l}174(81.3) \\
40(18.7)\end{array}$ & $\begin{array}{l}274(80.1) \\
68(19.9)\end{array}$ & $\begin{array}{l}1.00 \text { (reference) } \\
0.93(0.60,1.43)\end{array}$ & $\overline{-}$ & & \\
\hline Rs683I280 & & & & & & & \\
\hline Wild & GG & $71(66.4)$ & $77(45.0)$ & 1.00 (reference) & - & 1.00 (reference) & - \\
\hline Heterozygote & GA & $31(29.0)$ & $78(45.6)$ & $0.34(0.12,0.97)$ & 0.044 & $0.36(0.13,1.06)$ & 0.064 \\
\hline Homozygote & AA & $5(4.7)$ & $16(9.4)$ & $0.43(0.26,0.73)$ & 0.002 & $0.43(0.25,0.74)$ & 0.002 \\
\hline Dominant & $\begin{array}{l}\mathrm{GG} \\
\mathrm{GA}+\mathrm{AA}\end{array}$ & $\begin{array}{l}71(66.4) \\
36(33.6)\end{array}$ & $\begin{array}{l}77(45.0) \\
94(55.0)\end{array}$ & $\begin{array}{l}\text { I.00(reference) } \\
\mathbf{0 . 4 2 ( 0 . 2 5 , 0 . 6 9 )}\end{array}$ & $-\overline{0.001}$ & $\begin{array}{l}\text { I.00(reference) } \\
\mathbf{0 . 4 2 ( 0 . 2 5 , 0 . 7 0 )}\end{array}$ & $\overline{0.001}$ \\
\hline Recessive & $\begin{array}{l}\text { GG+GA } \\
\mathrm{AA}\end{array}$ & $\begin{array}{l}102(95.3) \\
5(4.7)\end{array}$ & $\begin{array}{l}155(90.6) \\
16(9.4)\end{array}$ & $\begin{array}{l}\text { I.00(reference) } \\
0.48(0.17,1.34)\end{array}$ & $\overline{0.158}$ & $\begin{array}{l}\text { I.00(reference) } \\
0.52(0.18,1.47)\end{array}$ & $\overline{0.214}$ \\
\hline Allele & $\begin{array}{l}G \\
A\end{array}$ & $\begin{array}{l}173(80.8) \\
4 \mid(19.2)\end{array}$ & $\begin{array}{l}232(67.8) \\
110(32.2)\end{array}$ & $\begin{array}{l}\text { I.00(reference) } \\
\mathbf{0 . 5 0}(0.33,0.75)\end{array}$ & $\begin{array}{l}- \\
0.001\end{array}$ & & \\
\hline
\end{tabular}

Notes: Bold values are statistically significant $(P<0.05)$. *Adjust for age, body mass index and diabetes mellitus. 
However, the incidence of the A allele, GA+AA genotype, or AA genotype of IDUA rs6831280 polymorphism was higher in responders than in non-responders (A vs G: OR, $0.50 ; 95 \%$ CI, 0.33-0.75; $P=0.001)$. The findings remained significant after adjusting for age, BMI, and diabetes mellitus. This indicated that ZA treatment was more effective in individuals with the A allele.

\section{Discussion}

In this study, we found that IDUA rs3755955/rs6831280 polymorphisms increased the risk of OP in a population of Chinese women. Furthermore, IDUA rs3755955 polymorphism in women with OP was associated with a younger age and lower lumbar spine BMD. Finally, IDUA rs6831280 polymorphism caused differences in individual sensitivity to ZA treatment for OP.

Protein phosphorylation is the most basic, universal, and most important mechanism for regulating and controlling protein vitality and function. ${ }^{11}$ Protein phosphorylation occurs mainly in two amino acids: serine (including threonine), and tyrosine. ${ }^{11}$ Gene polymorphisms that create, alter, or destroy phosphorylation sites have been recognized as functional variants for human diseases, such as prostate cancer (TP53 rs1042522) ${ }^{12}$ and tuberculosis (TLR2 rs5743708). ${ }^{13} \mathrm{Niu}$ et al found that IDUA phosphorylation-related SNPs rs3755955 and rs6831280 exert indirect effects on nearby phosphorylation sites, which could affect the risk of OP. ${ }^{6}$

Wang et al recruited 172 OP patients with lowtraumatic fractures and $156 \mathrm{OP}$ patients without fracture to investigate the relationship of two SNPs (rs3755955 and rs6831280) with BMD and fractures. ${ }^{9}$ They found that BMDs at lumbar spine L2-L4 and total hip among subjects with the GA genotype of rs6831280 polymorphism were lower than those among subjects with the GG or AA genotype carriers. ${ }^{9}$ IDUA rs6831280, and not rs3755955, polymorphism is a genetic risk factor for osteoporotic fractures. ${ }^{9}$ Our results revealed that IDUA rs3755955 and rs6831280 polymorphisms increased the susceptibility of postmenopausal women to OP. Individuals with the AA genotype of rs3755955 polymorphism had the lowest lumbar spine BMD compared with GA or GG genotype. Notably, this study focused on the association of IDUA gene polymorphisms with OP, but not with fractures. Furthermore, our study demonstrated that IDUA rs3755955 polymorphism is associated with BMD at lumbar spine, instead of rs 6831280 polymorphism reported by Wang et al. ${ }^{9}$ This inconsistency may be attributed to geographical differences (Northern and Southern), dietary differences, and population heterogeneity. A single infusion of intravenous ZA decreases bone turnover and improves BMD after 12 months in postmenopausal women with $\mathrm{OP}^{10}$ and significantly reduces the risk of vertebral, hip, and other fractures. ${ }^{14}$ Since IDUA rs3755955 and rs6831280 polymorphisms were associated with lumbar spine BMD, our study evaluated the effect of these SNPs on the sensitivity to ZA. There was no significant difference between responders and non-responders to ZA treatment in the allelic and genotypic distribution of the rs3755955 polymorphism. However, we could not rule out the possibility of false-positive results because of a small sample size. Nevertheless, the A allele frequency of rs6831280 polymorphism in participants with OP was significantly higher than that in healthy controls. Therefore, mutant genotypes were more sensitive to ZA, and the increased treatment effect was significant. To the best of our knowledge, this study is the first to evaluate the association between IDUA gene polymorphisms and ZA treatment, and may serve to guide further studies in this field.

Several potential limitations of our study merit careful consideration. First, the sample size was relatively small, which could have produced false-positive or false-negative results. Second, this study only genotyped two SNPs of the $I D U A$ gene and the coverage of this gene was incomplete. Third, we did not include many risk factors for OP (eg, smoking and history of personal fractures) into consideration because of the limited data availability. Finally, these results should be validated in other populations in China and in other countries.

In conclusion, our group identified a significant association between IDUA gene polymorphisms and OP. Further studies with larger sample sizes in other races and ethnicities are urgently warranted to identify the genetic profile of individuals with OP.

\section{Data Sharing Statement}

The datasets used and/or analyzed during the current study are available from the corresponding author on reasonable request.

\section{Acknowledgments}

This study was supported by the National Natural Science Foundation of China (81702179), Funding from Young Talent Development Plan of Changzhou Health Commission (CZQM2020059), Science and Technology 
Plan Project of Changzhou (CJ20190002), and Zhejiang Medicine and Health Technology Plan (2020KY313).

\section{Disclosure}

No potential conflict of interest was reported by the authors.

\section{References}

1. Eastell R, O’Neill TW, Hofbauer LC, et al. Postmenopausal osteoporosis. Nat Rev Dis Primers. 2016;2:16069. doi:10.1038/ nrdp.2016.69

2. Rizzoli R. Postmenopausal osteoporosis: assessment and management. Best Pract Res Clin Endocrinol Metab. 2018;32(5):739-757. doi:10.1016/j.beem.2018.09.005

3. Black DM, Rosen CJ, Solomon CG. Postmenopausal osteoporosis. N Engl J Med. 2016;374(18):1797. doi:10.1056/NEJMx160008

4. Watts NB. Postmenopausal osteoporosis: a clinical review. $J$ Womens Health (Larchmt). 2018;27(9):1093-1096. doi:10.1089/jwh.2017.6706

5. Baccaro LF, Conde DM, Costa-Paiva L, Pinto-Neto AM. The epidemiology and management of postmenopausal osteoporosis: a viewpoint from Brazil. Clin Interv Aging. 2015;10:583-591. doi:10.2147/CIA.S54614

6. Niu T, Liu N, Yu X, et al. Identification of IDUA and WNT16 phosphorylation-related non-synonymous polymorphisms for bone mineral density in meta-analyses of genome-wide association studies. J Bone Miner Res. 2016;31(2):358-368. doi:10.1002/jbmr.2687

7. Kuehn SC, Koehne T, Cornils K, et al. Impaired bone remodeling and its correction by combination therapy in a mouse model of mucopolysaccharidosis-I. Hum Mol Genet. 2015;24(24):7075-7086. doi: $10.1093 / \mathrm{hmg} / \mathrm{ddv} 407$
8. Zhou Z, Gao M, Liu Q, Tao MD. Comprehensive transcriptome analysis of mesenchymal stem cells in elderly patients with osteoporosis. Aging Clin Exp Res. 2015;27(5):595-601. doi:10.1007/s40520-015-0346-z

9. Wang Q, Tang C, Jia J, Zhang G, Liu Z. Associations of IDUA and PTCH1 with bone mineral density, bone turnover markers, and fractures in Chinese elderly patients with osteoporosis. Dis Markers. 2019;2019:9503762. doi:10.1155/2019/9503762

10. Dhillon S. Zoledronic acid $(\operatorname{Reclast}((\mathrm{R}))$, Aclasta((R))): a review in osteoporosis. Drugs. 2016;76(17):1683-1697. doi:10.1007/s40265016-0662-4

11. Humphrey SJ, James DE, Mann M. Protein phosphorylation: a major switch mechanism for metabolic regulation. Trends Endocrinol Metab. 2015;26(12):676-687. doi:10.1016/j.tem.2015.09.013

12. Fan S, Hao ZY, Zhang M, Liang CZ. Association between the rs1042522 polymorphism in TP53 and prostate cancer risk: an updated meta-analysis. Chronic Dis Transl Med. 2017;3(2):95-104. doi:10.1016/j.cdtm.2017.04.001

13. Cubillos-Angulo JM, Arriaga MB, Silva EC, et al. Polymorphisms in TLR4 and TNFA and risk of mycobacterium tuberculosis infection and development of active disease in contacts of tuberculosis cases in Brazil: a prospective cohort study. Clin Infect Dis. 2019;69 (6):1027-1035. doi:10.1093/cid/ciy1001

14. Black DM, Delmas PD, Eastell R, et al. Once-yearly zoledronic acid for treatment of postmenopausal osteoporosis. $N$ Engl $J$ Med. 2007;356(18):1809-1822. doi:10.1056/NEJMoa067312
Pharmacogenomics and Personalized Medicine

\section{Publish your work in this journal}

Pharmacogenomics and Personalized Medicine is an international, peer-reviewed, open access journal characterizing the influence of genotype on pharmacology leading to the development of personalized treatment programs and individualized drug selection for improved safety, efficacy and sustainability. This journal is indexed

\section{Dovepress}

on the American Chemical Society's Chemical Abstracts Service (CAS). The manuscript management system is completely online and includes a very quick and fair peer-review system, which is all easy to use. Visit http://www.dovepress.com/testimonials.php to read real quotes from published authors. 